Western University Scholarship@Western

Research Program. Impact of the Public Sector on

Research Program. Impact of the Public Sector on

Local Economies Discussion Papers

Local Economies

1975

\title{
The Timing of Residential Land Development: A General Equilibrium Approach
}

James R. Markusen

David T. Scheffman

Follow this and additional works at: https://ir.lib.uwo.ca/economicsipsle_dp

Part of the Economics Commons

Citation of this paper:

Markusen, James R., David T. Scheffman. "The Timing of Residential Land Development: A General Equilibrium Approach."

Research Program. Impact of the Public Sector on Local Economies Discussion Papers, 005. London, ON: Department of Economics, University of Western Ontario (1975). 
Discussion Paper 005

THE TIMING OF RESIDENTIAL LAND DEVELOPMENT:

A GENERAL EQUILIBRIUM APPROACH

James R. Markusen

David T. Scheffman

\section{RESEARCH PROGRAM: IMPACT OF THE PUBLIC SECTOR ON LOCAL ECONOMIES}
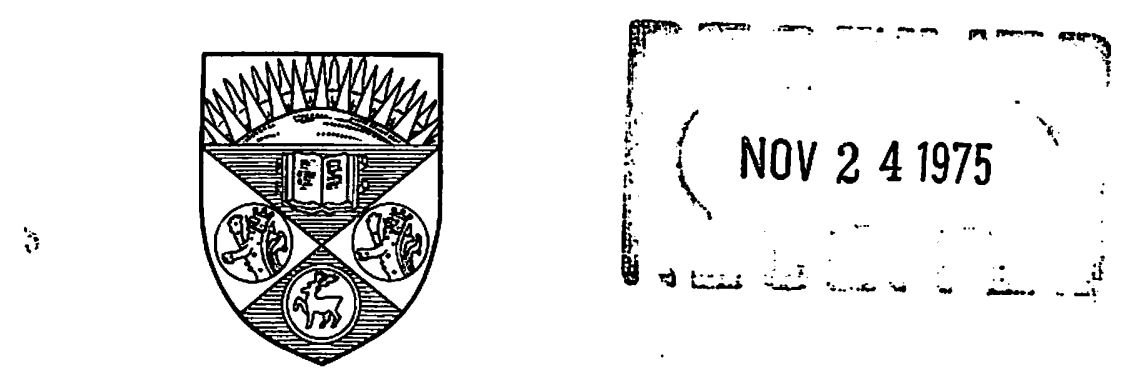

\section{Department of Economics} The University of Western Ontario London Ontario Canada 


\section{Discussion Paper 005}

\section{THE TIMING OF RESIDENTIAL LAND DEVELOPMENT: \\ A GENERAL EQUILIBRIUM APPROACH \\ James R. Markusen \\ David T. Scheffman}

November, 1975 


\title{
THE TIMING OF RESIDENTIAL LAND DEVELOPMENT:
}

\section{A GENERAL EQUILIBRIUM APPROACH*}

\author{
James R. Markusen
}

David T. Scheffman

\section{Introduction}

Rapidly rising residential 1 and prices in major North American metropolitan areas have generated a growing amount of public discussion and occasional legislative action. Implicit in much of this discussion seems to be the notion that this rise in land prices is at least partly attributable to the existence of a group of 1 and developers or "speculators." 1 These developers are thought to cause high land prices insofar as they withhold land from sale to builders in hopes of higher prices in the future. The result of this type of investment or speculative behavior is said to be socially undesirable in that it implies a slower rate of land development and higher land prices than are socially acceptable. Further, this process is thought to result in a redistribution of income away from the community at large in favour of the 1 and developers. It is not unnatural, therefore, that this conceptual model of 7 and development should result in legislation to speed development, reduce land prices, and tax away capital gains realized by 1 and developers and other 1 and investors. ${ }^{2}$

The 1 and development process is not we11 understood, however, and many of our ideas about the 1 and market are borrowed from analyses of other types of markets. ${ }^{3}$ These ideas, which form the foundation of our legislative proposals, may be inappropriate for a number of reasons. Unlike housing units or capital goods, for example, the supply of land of given 
characteristics (e.g., commuting distance to the city centre) is fixed in the long run in any metropolitan area. Any decision to develop land for residential use, therefore, necessarily reduces the total stock of undeveloped 1 and with these characteristics by the amount of 1 and developed. Since 1 and developer's timing of transactions will clearly reflect this fact, any analysis of 1 and pricing ought to be placed in a dynamic framework.

Perhaps the most important difference between the 1 and market and other markets occurs on the demand side. Consumers receive satisfaction from the flow of services derived from the stock of residential land they own. Theflow demand for new residential land in any period is best thought of as a stock adjustment demand. Further, there is virtually no depreciation on 1 and. This implies that increased sales of developed land in the current period wil1, ceteris paribus, decrease the demand for new residential land in future periods. A developer must realize that sales of 1 and by competitors in the present period will affect the future demand for, and therefore the value of his holdings.

This paper will examine these issues by constructing a formal model of the development process in order to arrive at a better understanding of the timing of residential 1 and development, the change in 1 and prices over time, and the effects of various legislative actions on these variables. of particular interest will be the relationship between market structure and land prices and the timing of land development. The paper demonstrates that with land in fixed supply, a monopolist is less likely to develop all his 1 and than a competitive development industry within a given time horizon. If demand is sufficient for a monopolist to profitably develop al1 his 1and, however, monopoly generally cannot lead to both a slower rate of development and a steeper rate of price appreciation than would occur 


\section{$-3-$}

under conditions of competition.

Other results of the paper include a demonstration that the institution of a property tax or a capital gains tax must reduce the initial period price of developed land in a competitive situation. It is further shown that a capital gains tax will lead to a higher rate of land development and a higher rate of price appreciation than would prevail in the absence of the tax. Questions of tax incidence and the distinction between Ricardian rents and returns to market power are also dealt with.

The model presented here makes a number of simplifying assumptions in order to focus clearly on the intertemporal patterns of 1 and sales and land prices in a general equilibrium framework. ${ }^{4}$ Perhaps most important, land is assumed to be homogeneous (both physically and spatially) and in fixed supply. Therefore, a 11 land transacted in a given time period must bear the same price. An indirect justification of this approach, which considerably simpiifies the mathematical complexity of the model, can be found in Markusen and Scheffman (1975a). In that paper, the authors argue that a meaningful measure of ownership concentration in the urban land market should be formulated in terms of subsets of relatively homogeneous 1and. A static spatial model is then used to demonstrate that a landowner who owns a "large" percentage of all land at a fixed commuting distance from the city always has potential market power regardless of how small his holdings are as a percentage of all urban land.

\section{Demand for Residential Land}

Let us begin by constructing a two-period model in which a fixed stock of land, initially held by a group referred to as developers, is prepared for residential construction and sold to consumers over the course 
of two time periods. ${ }^{5}$ It is perhaps conceptualiy useful to think of these two periods as being the present and future, and therefore the periods are not necessarily of equal length. Developers may perform servicing functions such as subdivision, sewer installation, and road building, so serviced 1 and will be referred to as developed land. It is assumed that consumers have no alternative sources of 1 and and that consumers contract for housing construction once they have purchased 1 and. ${ }^{6}$ The purpose of this assumption is to keep a clear distinction between 1 and and housing prices, the former being the focus of this paper.

Let us first consider the determinants and properties of the demand for 1 and of an individual consumer. If we conceive of our model as a small community in the middle of a large free trade region, we can assume that all commodities are traded with the region and the commodity prices to the small community are fixed. These prices are then independent of the price of land, the distribution of income, etc. Various types of housing units that consumers can construct on their land are numbered among these commodities. This assumption that commodity prices are fixed to the community allows us to make use of the composite commodity theorem to aggregate all commodities into a single composite commodity and to express preferences as a function of the composite commodity and the stock of 1 and held by the consumer. ${ }^{7}$ Denoting the composite commodity purchased in time $T$ as $C_{T}$ and the purchase of $l$ and in time $T$ as $L_{T}$, the consumer's two period utility function is given by:

$$
U=U_{0}\left(C_{0}, L_{0}\right)+U_{1}\left(C_{1}, L_{0}+L_{1}\right)
$$

where $U_{i}$ gives the present value of the flow of utility at $T=i$ and where $U_{i}$ is assumed to have the usual quasi-concave properties. Additivity is 
assumed only for the convenience of graphical exposition. $\left(L_{0}+L_{1}\right)$ appears as an argument in $U_{1}$ since utility at time $T=1$ is derived from the total amount of 1 and owned by the consumer and not just from 1 and purchased at $T=1$. It is important to remember in what follows that $L_{7}$ is the incremental demand for 1 and in period 1 . A final assumption of this formulation is that land does not depreciate.

The composite commodity is used as numeraire and community income in period $T$ in terms of $C_{T}$ is denoted $Y_{T}{ }^{8}$ where $Y_{T}$ is known with certainty. $\mathrm{P}_{\mathrm{T}}$ will denote the price of 1 and in period $T$ in terms of $C_{T}$.

The consumer makes consumption plans for both periods by maximizing his two period utility function subject to a budget constraint that discounts future income and expenditures at a rate $i$. This rate may be an actual mortgage rate or it may include an added premium for risk. ${ }^{9}$ In either case, the budget constraint al lows the consumer to borrow or lend subject only to the condition that the present value of the income stream equal the present value of the expenditure stream. The consumer's demand functions are then given as the solution of the problem:

$$
\begin{aligned}
& \operatorname{Max} U_{0}\left(C_{0}, L_{0}\right)+U_{1}\left(C_{1}, L_{0}+L_{1}\right) \\
& \text { s.t. }\left(Y_{0}+Y_{1}(1+i)^{-1}-C_{0}-C_{1}(1+i)^{-1}-p_{0} L_{0}-p_{1}(1+i)^{-1} L_{7}\right)=0
\end{aligned}
$$

The first order necessary conditions for a maximum are given as follows: 
(3)

$$
\begin{aligned}
& \frac{\partial}{\partial C_{0}}=U_{01}-\lambda \leq 0 \\
& \frac{\partial}{\partial L_{0}}=U_{02}+U_{12}-\lambda p_{0} \leq 0 \\
& \frac{\partial}{\partial C_{1}}=U_{11}-\lambda(1+i)^{-1} \leq 0 \\
& \frac{\partial}{\partial L_{1}}=U_{12}-\lambda p_{1}(1+i)^{-1} \leq 0
\end{aligned}
$$

plus the constraint condition. Two results are of particular interest:

$$
\begin{aligned}
& \frac{U_{02}+U_{12}}{U_{01}}=p_{0} \quad \text { if } C_{0}, L_{0}>0 \\
& \quad \text { if } p_{0}-p_{1}(1+i)^{-1} \leq 0 \text { then } L_{1}=0
\end{aligned}
$$

The first equation in (4) states that the marginal rate of substitution between $L_{0}$ and $C_{0}$ will be less than $p_{0}$. Since $L_{0}$ also gives utility at $T=1$, $L_{0}$ is purchased past the point where the usual marginal rate of substitution condition holds. The second equation in (4) states that if the price of land is growing as fast as the rate of interest, consumers will wish to purchase all land in $T=0$ since the cost of borrowing is less than the costs imposed by price appreciation.

This situation is shown in Figure I where it is assumed for convenience that $Y_{0}=Y_{1}, p_{0}=p_{1}$, and that the consumer does not choose to borrow or lend. The budget line in $T=0$ is given by $Y_{0} B$ and the optimal consumption bundle, characterized by the marginal rate of substitution less than the price ratio, in $T=0$ is given by $A$. The consumption bundle for 
$-7-$

Figure I

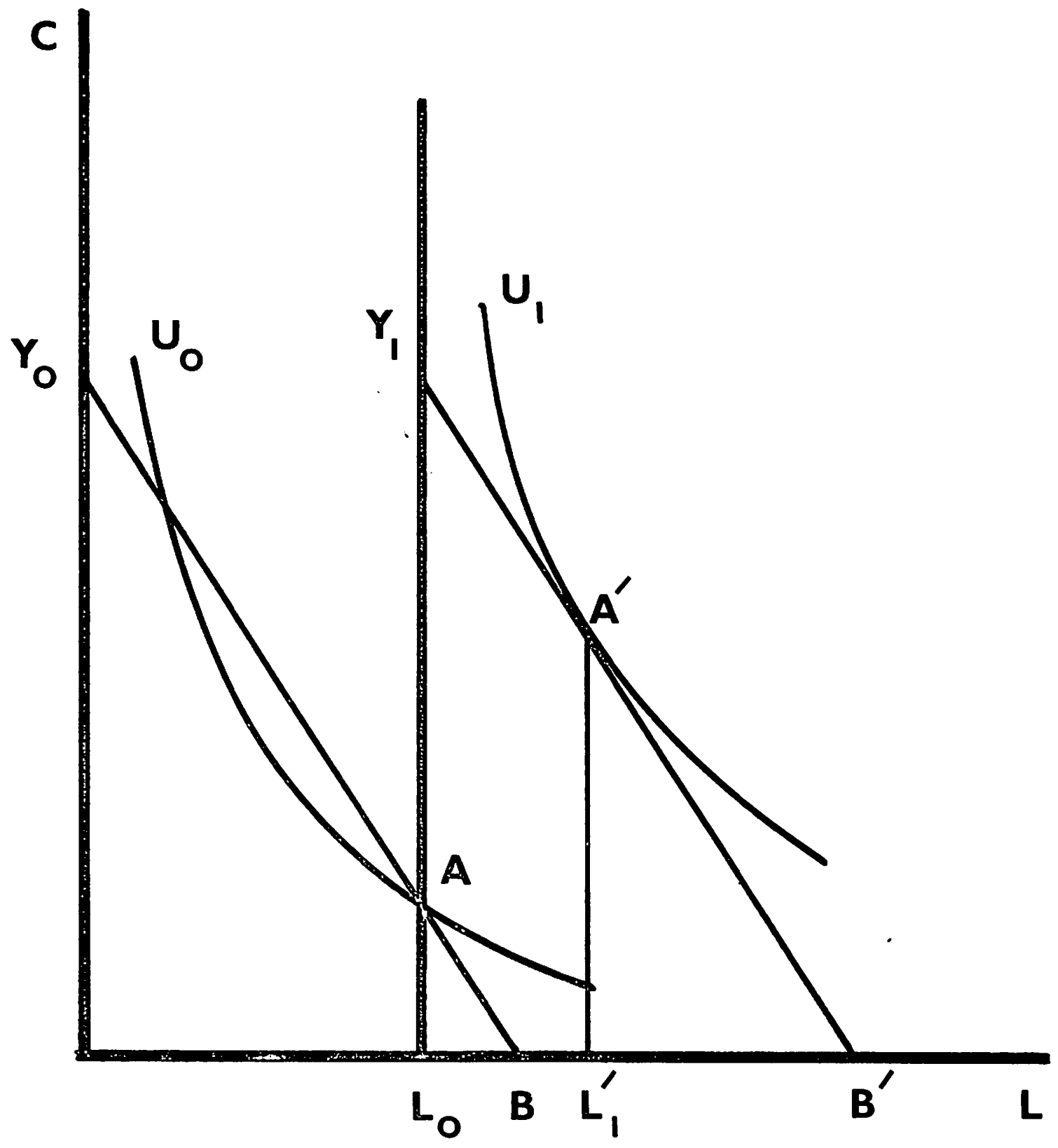


$T=1$ is found by shifting the budget line to $Y_{7} B^{\prime}$. The optimal consumption bundle is now given by point $A^{\prime}$ with purchases of 1 and in $T=1$ equal to $\left(L_{1}{ }^{\prime}-L_{0}\right)$. The sum of $U_{0}$ and $U_{1}$ give the consumer's total wel fare from this allocation. Borrowing an amount $X$ at $T=0$ can be conveniently represented in this diagram by a parellel shift out of $Y_{0} B$ an amount $X$ on the vertical axis and a parallel shift of $Y_{1} B^{\prime}$ equal to $X(1+i)$ in the opposite direction. Our discussion of the demand functions of an individual consumer lead us to specify market demand functions of the form

$$
L_{0}=D_{0}\left(p_{0}, p_{1}, \underline{Y}_{0}, \underline{Y}_{1}, i\right)
$$

$$
L_{1}=D_{1}\left(p_{0}, p_{1}, \underline{Y}_{0}, \underline{Y}_{1}, i\right)
$$

where $\underline{Y}_{T}$ is the vector of incomes of consumers at time $T$. Assuming that both $C_{j}$ and $L_{i}$ are normal goods, $\left(\partial D_{i} / \partial p_{i}\right)<0$. The properties of these demand functions are discussed in more detail in Appendix I. It is sufficient to note here that two additional properties of these demand functions are assumed to hold for the remainder of the paper. First, it is assumed that an increase in the price of land in either period diminishes the total two period demand for 1 and. In other words, $\partial\left(L_{0}+L_{7}\right) / \partial p_{i}<0$, for $i=0,1$. What is ruled out is the possibility that an increase in $p_{0}$, for example, will lead to an increase in $L_{1}$ that outweighs the decrease in $L_{0}$. Although this seems to be a reasonable assumption, it is not implied by our previous assumptions. Second, we assume that 1 and in different periods are gross substitutes, i.e., $\partial D_{i} / \partial p_{j}>0, i \neq j$. 


\section{Supply by Developers - Perfect Competition}

Developers in this urban area own an amount of 1 and, $\bar{L}$, which is assumed to encompass the totality of developable 1 and. In this section we assume that each developer owns only a small amount of $[$, so that developers can be assumed to be price takers. The prices of developed land at time zero and one, $p_{0}$ and $p_{1}$, are assumed to be known with certainty.

In each period a developer can develop and sell any part of his holdings. The costs of development per unit of 1 and are assumed to be constant and identical in each period, and will be denoted by s. This constant is used to represent such costs as lot servicing and subdivision approval. Any land not developed in a given period earns a return from agricultural production which is assumed to be a constant per unit of land and identical in each period. This agricultural return is denoted by $q$. Land which is developed during a particular period does not earn any return from agricul tural use.

The rate of return on assets judged by developers to be equivalent to 1 and will be denoted by $r$. The supply of land in each period can now be described as the solution of the problem

$$
\begin{aligned}
& \max _{\left\{L_{0}, L_{1}\right\}} p_{0} L_{0}+p_{1}(1+r)^{-1} L_{1}-s L_{0}-s(1+r)^{-1} L_{1} \\
& +q\left(\bar{L}-L_{0}\right)+q(1+r)^{-1}\left(\bar{L}-L_{0}-L_{1}\right) \\
& \text { s.t. } L_{0}+L_{1}-\left[\leqq 0 ; L_{0}, L_{1} \geqq 0\right.
\end{aligned}
$$

The first order conditions for a maximum are ${ }^{10}$ 


$$
\begin{aligned}
& \partial / \partial L_{0}=p_{0}-s-q-q(1+r)^{-1}-\lambda \leqq 0 \\
& \partial / \partial L_{1}=(1+r)^{-1}\left[p_{1}-s-q\right]-\lambda \leqq 0 \\
& L_{0}+L_{1}-[\leqq 0
\end{aligned}
$$

where $\lambda$ is the Lagrangean multiplier associated with the constraint on developable land, with $\lambda \geqq 0$.

The first order conditions require that a necessary condition for land to be developed in period $i$, is that the present value of land developed net of development costs, $\Sigma\left(p_{j}-s_{j}\right)(1+r)^{-i}$, must be at least as large as the present value of the land in agricultural use, $\sum_{j=i}^{1} q(1+r)^{-j}$. If $\lambda>0$, then all land is sold over the course of the two periods and $\lambda$ can be interpreted as the Ricardian rent required for 1 and to be sold at time zero. In this case (7) can be interpreted as requiring that Ricardian rents appreciate at rate $r$ for 1 and to be supplied in each period. Notice that even if all land is not sold in period zero, the land sold in that period can still earn positive Ricardian rents. This result is contrary to the usual analysis of Ricardian rents in static models, where the Ricardian factor can only earn positive rents if demand calls for the total supply. This is another indication of the inappropriateness of using static models to analyze land markets.

Since developed land typically commands a price above its opportunity cost in agriculture, for the remainder of this paper we will assume that $\lambda>0$. Therefore all land will be developed over the two period horizon. In this case (7) requires that the Ricardian rent at time zero, $\lambda$, must grow at rate $r$ for 1 and to be sold in each period. Assuming $\lambda>0$, the first two equations of (7) give us the following supply characteristics: 
(8a)

$$
\left(L_{0}, L_{1}\right)=\left\{\begin{array}{l}
\left([, 0), \text { if } p_{0}-p_{1}(1+r)^{-1}>q+\left[s-s(1+r)^{-1}\right]\right. \\
(0, \bar{L}), \text { if } p_{0}-p_{1}(1+r)^{-1}<q+\left[s-s(1+r)^{-1}\right] \\
\left(L_{0},\left[-L_{0}\right), L_{0} \geqq 0, \text { if } p_{0}-p_{1}(1+r)^{-1}=q+\left[s-s(1+r)^{-1}\right]\right.
\end{array}\right.
$$

This can also be written

$$
\left(L_{0}, L_{1}\right)=\left\{\begin{array}{l}
(\bar{L}, 0), \text { if } \frac{p_{1}-p_{0}}{p_{0}}<r-[q(1+r)+s r] / p_{0} \\
(0, \bar{L}), \text { if } \frac{p_{1}-p_{0}}{p_{0}}>r-[q(1+r)+s r] / p_{0} \\
\left(L_{0}, \bar{L}-L_{0}\right), L_{0} \geq 0, \text { if } \frac{p_{1}-p_{0}}{p_{0}}=r-[q(1+r)+s r] / p_{0}
\end{array}\right.
$$

The interpretation of (8a) and (8b) is straightforward. If land is sold in each period then the rate of price appreciation must be less than $r$, with the equilibrium rate of price appreciation being an increasing function of $p_{0}$, or equivalently, of $\lambda$. Alternatively, developers will be indifferent to sales in the two periods if the difference between the present price of developed 7 and $\left(p_{0}\right)$ and the present value of future price $\left(p_{1}(1+r)^{-1}\right)$ is just equal to the agricultural revenue foregone by developing at $T=0$ instead of $T=l(q)$ plus the burden of incurring development costs at $T=0$ rather than at $T=1\left(s-s(1+r)^{-1}\right)$.

Notice that in an equilibrium where land is sold in each period, prices may fall. This is explained by the fact that although equilibrium requires Ricardian rents to appreciate, since the present value of agricultural production at $T=1$ is less than the present value at $T=0$, developers may not develop at $T=0$ unless $p_{0}$ exceeds $p_{1}$. However, the rate of change of prices is algebraically larger the higher the price of developed 1 and $\left(p_{0}\right)$ 
relative to the yearly return from agriculture $(q)$. As developed land becomes more and more valuable, positive land sales in each period require a positive rate of price appreciation approaching $r$, the rate of return on equivalent assets.

\section{Market Equilibrium}

Given the assumption that demand is sufficient for all land to be developed in the two periods, the following equilibrium conditions will obtain in the land market:

$$
\begin{aligned}
& D_{0}=S_{0} \\
& D_{1}=S_{1} \\
& D_{0}+D_{1}=S_{0}+S_{1}=\tau
\end{aligned}
$$

where $S_{i}$ denotes market supply in period $i$. Assuming positive sales in each period for the moment, we also have the supply condition:

$$
P_{0}=p_{1}(1+r)^{-1}+q+\left[s-s(1+r)^{-1}\right]
$$

or

$$
p_{1}=p_{0}(1+r)-q(1+r)-r s
$$

For fixed values of $\gamma_{i}$, we can use equation (5) to write our equilibrium condition as follows:

$$
D_{0}\left(p_{0}, p_{0}(1+r)-q(1+r)-r s\right)+D_{1}\left(p_{0}, p_{0}(1+r)-q(1+r)-r s\right)=[
$$

Equation (11) reduces the equilibrium conditions to a single equation in one unknown $\left(p_{0}\right)$. 
A graphical representation of equation (11) is given in Figure II, where $D_{0}$ and $D_{1}$ are the first and second period demand curves. We have assumed that a rise in either $p_{0}$ or $p_{1}$ will, ceteris paribus, cause a decrease in the total demand for $L\left(\partial\left(L_{0}+L_{1}\right) / \partial p_{i}<0\right)$. But equation $(10)$ shows that positive land sales in each period require that $p_{1}$ be an increasing linear function of $p_{0}$. It follows, therefore, that the total excess demand for 1 and must decrease as $p_{0}$ increases. This condition is satisfied in Figure II where both $D_{0}$ and $D_{1}$ decrease as $p_{0}$ (and therefore $p_{1}$ ) increases. Equilibrium wi 11 be at the intersection of $D_{0}$ and $D_{1}$ provided that $Q=q\left(1+(1+r)^{-1}\right)+s$, representing total opportunity costs, is less than the value of $p_{0}$ at this intersection. $Q=Q^{\prime}$ in Figure II provides an example. If $Q=Q^{\prime \prime}$ in Figure II, not all of $\left[\right.$ will be developed and the equilibrium values of $L_{0}$ and $L_{1}$ will be given by the respective intersections of $D_{0}$ and $D_{1}$ with $Q "$. The solution shown in Figure II is not the only possibility that satisfies the requirement that increases in $p_{0}$ and $p_{1}$ reduce total excess demand. $D_{0}$ may be upward sloping provided that its slope is less than the absolute value of the slope of $D_{1}$. Similarly, $D_{1}$ may slope upward provided that its slope is less than the absolute value of the slope of $D_{0}$. These conditions are required by our assumption $d\left(L_{0}+L_{1}\right) / d p_{i}<0$, since $d D_{0}\left(p_{0}, p_{0}(1+r)-q(1+r)-r s\right) / d p_{0}+d D_{1}\left(p_{0}, p_{0}(1+r)-q(1+r)-r s\right) / d p_{0}$
$=\left[D_{00}+D_{10}\right]+(1+r)\left[D_{01}+D_{11}\right]=d\left(L_{0}+L_{1}\right) / d p_{0}+(1+r) d\left(L_{0}+L_{1}\right) / d p_{1}<0$.
A final possibility is that the two demand curves do not cross. If $D_{j}$ is the upper curve, a corner solution at $L_{i}=[$ will occur provided that the corresponding price exceeds $Q$. If the corresponding price is less than $Q$, equilibrium will occur at the value of $L_{i}$ where $p_{0}=Q$. 
Figure II

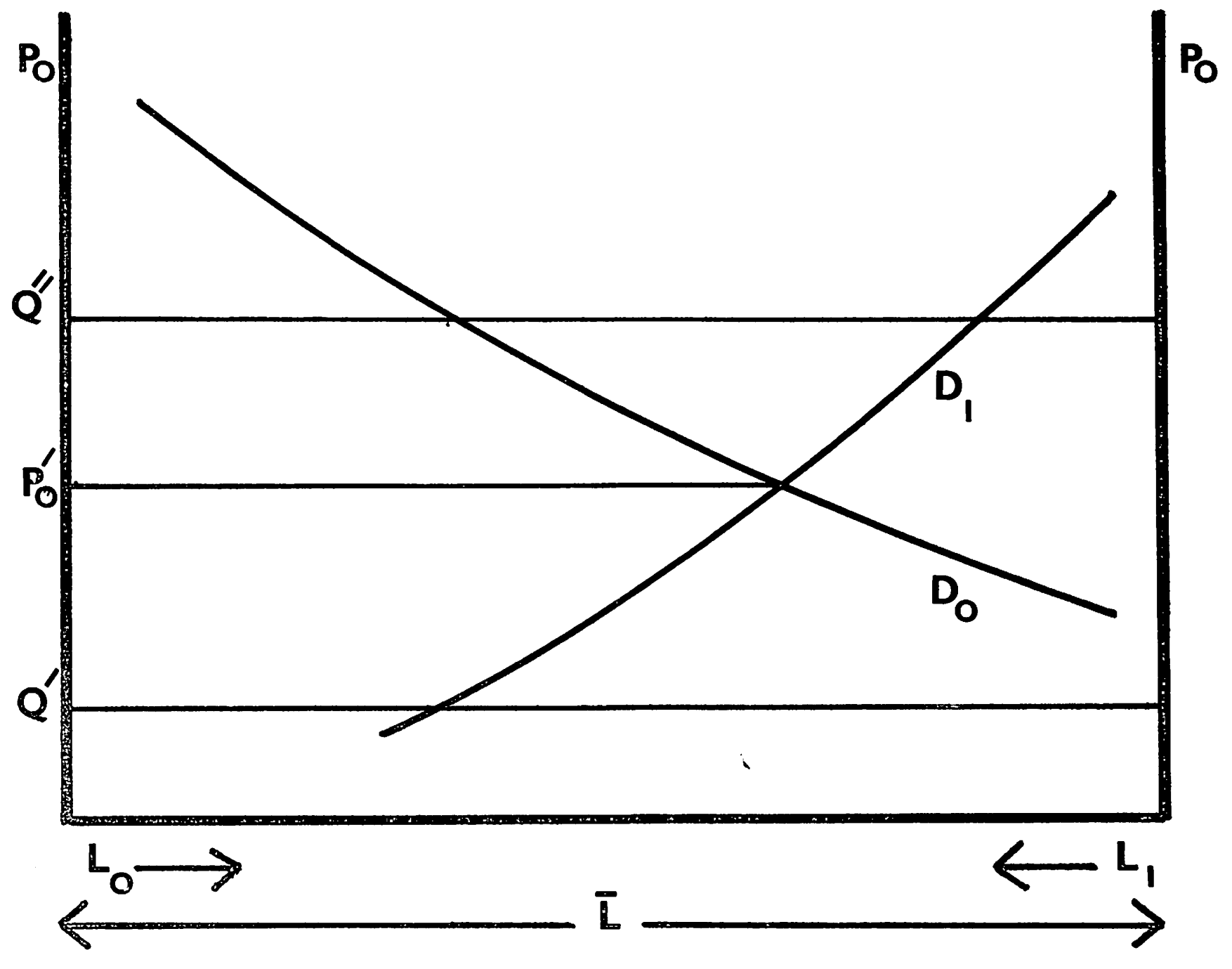




\section{Taxation and Market Equilibrium - Perfect Competition}

We will now consider the effect of two different types of taxes on the competitive equilibrium. First consider the effect of a property tax, assessed at an ad valorem rate $\tau$. We assume that developers are taxed on the developed value of their holdings, net of development costs, at the beginning of each period. Therefore competitive supply is given as the solution of

$$
\begin{aligned}
& \underset{\left\{L_{0}, L_{1}\right\}}{\max } p_{0} L_{0}+p_{1}(1+r)^{-1} L_{1}-\tau\left(p_{0}-s\right)\left(L_{0}+L_{1}\right)-\tau\left(p_{1}-s\right)(1+r)^{-1} L_{1} \\
&-s L_{0}-s(1+r)^{-1} L_{1}+q\left(\left[-L_{0}\right)+q(1+r)^{-1}\left(\left[-L_{0}-L_{1}\right)\right.\right. \\
& \text { s.t. } L_{0}+L_{1}-\left[\leqq 0 ; L_{0}, L_{1} \geqq 0\right.
\end{aligned}
$$

Assuming that demand is sufficient for all land to be developed and for some 1 and to be developed in each period, the first order conditions require

$$
p_{0}-p_{1}(1+r)^{-1}(1-\tau)=q+\left[s-s(1+r)^{-1}(1-\tau)\right]
$$

We assume that consumers must pay property $\operatorname{tax}$ at $T=1$ on the value (at $T=1$ ) of 1 and purchased at $T=0$. Therefore the discounted value of their property tax payments is $\tau p_{1}(1+r)^{-1} L_{0}$. This tax then has the effect of changing the consumer's price of $L_{0}$ from $p_{0}$ to $p_{0}+\tau p_{1}(1+r)^{-1}$. Therefore $D_{i}=D_{j}\left(p_{0}+\tau p_{1}(1+r)^{-1}, p_{1}\right)$. For demand to be sufficient for a11 1 and to be developed we must have

$$
D_{0}\left(p_{0}+\tau p_{1}(1+r)^{-1}, p_{1}\right)+D_{1}\left(p_{0}+\tau p_{1}(1+r)^{-1}, p_{1}\right)=\bar{L}
$$

Differentiating (13) and (14) with respect to $\tau$, 


$$
\begin{gathered}
\mathrm{dp}_{0} / \mathrm{d} \tau-(1+r)^{-1}(1-\tau) \mathrm{dp}_{1} / \mathrm{d} \tau=\left(s-\mathrm{p}_{1}\right)(1+r)^{-1} \\
\begin{aligned}
\left(D_{00}-D_{10}\right) \mathrm{dp}_{0} / \mathrm{d} \tau & +\left[\left(D_{01}+D_{11}\right)+\left(D_{00}+D_{10}\right) \tau(1+r)^{-1}\right] \mathrm{dp} p_{1} / d \tau \\
= & -\left(D_{00}+D_{10}\right) p_{1}(1+r)^{-1}
\end{aligned}
\end{gathered}
$$

Solving for $\mathrm{dp}_{0} / \mathrm{d} \tau$ and $d p_{1} / \mathrm{d} \tau$ from $(15)$, we have

$$
\begin{aligned}
\mathrm{dp}_{0} / \mathrm{d \tau}= & {\left[\left(s-p_{1}\right)(1+r)^{-1}\left[\left(D_{01}+D_{11}\right)+\left(D_{00}+D_{10}\right) \tau(1+r)^{-1}\right]\right.} \\
& \left.-(1+r)^{-2}(1-\tau) p_{1}\left(D_{00}+D_{10}\right)\right] / \Delta \\
d_{1} / d \tau= & -s(1+r)^{-1}\left(D_{00}+D_{10}\right) / \Delta
\end{aligned}
$$

where $\Delta$ is the determinant of the matrix of coefficients of (15).

Given the assumption that a rise in $p_{i}$, ceteris paribus, reduces the total two period demand for land $\left(D_{i j}+D_{j i}<0\right)$, it follows that $d p_{0} / d \tau<0$, $\mathrm{dp}_{1} / \mathrm{d} \tau<0$. Thus the property tax reduces 1 and prices in both periods.

The first order conditions for (12) (assuming land is supplied in each period) can also be written

$$
\frac{p_{1}-p_{0}}{p_{0}}=r+\tau p_{1} / p_{0}-[q(1+r)+s(r+\tau)] / p_{0}
$$

Letting $\left(\frac{p_{1}-p_{0}}{p_{0}}\right)$ * be the equilibrium rate of price appreciation for $\tau=0$, and $\left(\frac{p_{1}-p_{0}}{p_{0}}\right)^{* *}$ be the corresponding rate for $\tau>0,(17)$ can be written

$$
\left(\frac{p_{1}-p_{0}}{p_{0}}\right)^{* *}=\left(\frac{p_{1}-p_{0}}{p_{0}}\right)^{*}+\tau\left(p_{1}-s\right) / p_{0}
$$

so that the imposition of a property tax increases the equilibrium rate of price appreciation. We would expect that this would result in a higher 
equilibrium value for $L_{0}$ and a lower value for $L_{1}$ than would occur in the absence of the tax. However, since $p_{0}$ and $p_{1}$ both fall, the effect on equilibrium supplies is ambiguous. 11

Next, we can consider a tax on realized capital gains such as the Ontario Land Speculation Tax. Assume that the value of land sales in period $T=1$ in excess of the value of that land had it been sold in period $T=0$ is subject to an ad valorem rate of the $\operatorname{tax} \theta$. Since development costs are constant, the developed price may be used as a base. Competitive supply is then given by the solution of the following problem:

$$
\begin{aligned}
& \max _{\left\{L_{0}, L_{1}\right\}} p_{0} L_{0}+p_{1}(1+r)^{-1} L_{1}-\theta\left(p_{1}-p_{0}\right)(1+r)^{-1} L_{1}-s L_{0} \\
& -s(1+r)^{-1} L_{1}+q\left(\bar{L}-L_{0}\right)+q(1+r)^{-1}\left(\bar{L}-L_{0}-L_{1}\right) \\
& \text { s.t. } L_{0}+L_{1}-\bar{L} \leqq 0 ; L_{0}, L_{1} \geqq 0
\end{aligned}
$$

where we restrict our treatment to the case where $p_{1}>p_{0}$. Assuming land is supplied in each period, the first order necessary conditions for an interior maximum give:

$$
p_{0}\left(1-\theta(1+r)^{-1}\right)-p_{1}(1+r)^{-1}(1-\theta)=q+\left(s-s(1+r)^{-1}\right)
$$

or

$$
\frac{p_{1}-p_{0}}{p_{0}}=\frac{r-[q(1+r)+s r] / p_{0}}{(1-\theta)}
$$

Differentiating (20) and (5), we have

$$
\begin{aligned}
& \frac{(1-\theta+r)}{(1-\theta)} \frac{d p_{0}}{d \theta}-\frac{d p_{1}}{d \theta}=\frac{p_{0}-p_{1}}{1-\theta} \\
& \left(D_{00}+D_{10}\right) \frac{d p_{0}}{d \theta}+\left(D_{01}+D_{11}\right) \frac{d p_{1}}{d \theta}=0 .
\end{aligned}
$$


Solving for $d p_{0} / d \theta$ and $d p_{1} / d \theta$ from (21),

$$
\begin{aligned}
& \mathrm{dp}_{0} / \mathrm{d} \theta=\left(\frac{\mathrm{p}_{0}-\mathrm{p}_{1}}{1-\theta}\right)\left(\mathrm{D}_{01}+\mathrm{D}_{11}\right) / \Delta \\
& \mathrm{dp}_{1} / \mathrm{d} \theta=\left(\frac{\mathrm{p}_{1}-\mathrm{p}_{0}}{1-\theta}\right)\left(D_{00}+D_{10}\right) / \Delta
\end{aligned}
$$

where $\Delta$ is the determinant of the matrix of coefficients of (21). Again assuming that $D_{i j}+D_{j i}<0$, we see that $d p_{0} / d \theta<0, d p_{1} / d \theta>0$. We can also write the second equation of $(20)$ as

$$
\left(\frac{p_{1}-p_{0}}{p_{0}}\right)^{* *}=(1-\theta)^{-1}\left(\frac{p_{1}-p_{0}}{p_{0}}\right)^{*}
$$

so that the tax also increases the equilibrium rate of price appreciation. Since we have assumed that $D_{i j}>0, i \neq j$ (our assumption of gross substitutes), it is easily seen that $\mathrm{dD}_{0} / \mathrm{d} \theta>0, \mathrm{dD}_{1} / \mathrm{d} \theta<0$.

The conclusion here is that, with a fixed stock of land that is to be developed within a given time horizon, a capital gains tax will speed the conversion of undeveloped land into final use. Coincident with this higher rate of development, will be a higher rate of increase in the price of 1 and over time than would occur in the absence of these taxes. If the assumptions of this model are a reasonable description of reality, government policymakers cannot hope to use this tax instrument to simultaneously reduce the rate of increase in 1 and prices and speed development. With 1 and in fixed supply, an increase in the rate of development in initial periods must be paid for by higher prices in later periods.

One final point worth noting concerns the incidence of these taxes. The usual result in a situation where a commodity is in completely inelastic supply is that the supplier bears all of the tax. This is not 
generally true in this model, since the intertemporal pattern of supply is altered even though total supply remains constant. The present value of consumer payments for $\left[\right.$ (equal to $p_{0} L_{0}+p_{1}(1+i)^{-1} L_{1}$ ) may either increase or decrease following the taxes depending upon the distribution of purchases between $T=0$ and $T=1$ and the change in the equilibrium price ratio, $p_{1} / p_{0}$. One possible situation for the capital gains tax is shown graphically in Figure III where $D_{i}$ and $D_{i}^{\prime}$ are, respectively, the before and after tax demand curves for period $i . p_{0}^{N}$ and $p_{0}^{\top}$ denote the before and after tax equilibrium prices. The producer equilibrium condition (20) for positive land sales in each period requires that $p_{1}$ increase for every value of $p_{0}$. Assuming that $L_{1}$ is a normal good, $D_{1}$ must decrease at every $p_{0}$ as shown in Figure III. Assuming $L_{0}$ and $L_{T}$ are gross substitutes, $D_{0}$ will increase at every $p_{0}$. Because $\partial\left(L_{0}+L_{1}\right) / \partial p_{1}<0$, the diagram must be as shown with $p_{0}^{\top}<p_{0}^{N}$.

As a final point, note that this tax on realized capital gains cannot cause a reduction in total land developed. The reason for this is given in equations (7), (8a), and (8b) which show that the equilibrium rate of price appreciation becomes negative as the equilibrium value of $p_{0}$ approaches Q. Since this implies negative capital gains, the tax cannot be effective in driving $p_{0}$ below $Q$.

6. Monopoly and Market Equilibrium ${ }^{12}$

As suggested earlier in the paper, a common notion seems to be that conditions of monopoly generally lead to a smaller supply and a higher price for the commodity in question. This section will investigate the rate of land sales to final users and the path of price increases over time under monopoly and compare the results to the competitive equilibrium 
Figure III

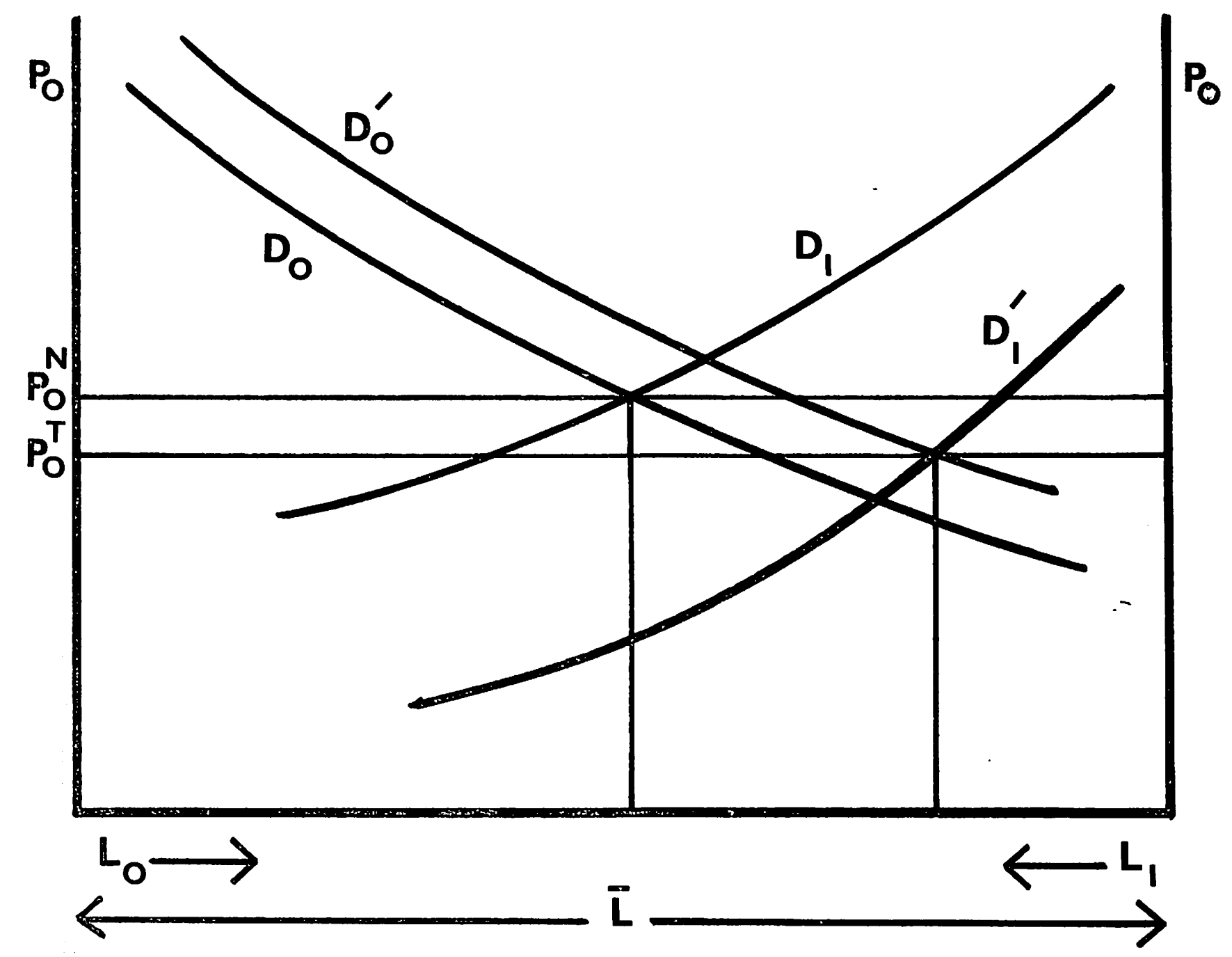


described earlier.

With incomes fixed, the demand functions in (4) can be expressed in inverse form by

$$
\begin{aligned}
& p_{0}=p_{0}\left(L_{0}, L_{1}\right) \\
& p_{1}=p_{1}\left(L_{0}, L_{1}\right)
\end{aligned}
$$

It follows from our earlier assumption that $\partial p_{i} / \partial L_{j}>0$ for $i \neq j$.

Profit maximizing sales by the monopolist are given as the solution of:

$$
\begin{aligned}
& \operatorname{Max}_{\left.0, L_{1}\right\}} P_{0}\left(L_{0}, L_{1}\right) L_{0}+p_{1}\left(L_{0}, L_{1}\right)(1+r)^{-1} L_{1}-s L_{0}-s(1+r)^{-1} L_{1} \\
& +q\left(\bar{L}-L_{0}\right)+q(1+r)^{-1}\left(\bar{L}-L_{0}-L_{1}\right) \\
& \text { s.t. } L_{0}+L_{1}-\left[\leqq 0 ; L_{0}, L_{1} \geqq 0\right. \text {. }
\end{aligned}
$$

If we define the marginal revenue of 1 and sales in period $i$ as the changes in the present value (evaluated at $T=i$ ) of total revenue with respect to the change in $L_{i}$, the first-order conditions for (25) can be expressed:

$$
\begin{aligned}
M R_{0} & =p_{0}+\frac{\partial p_{0}}{\partial L_{-}} L_{0}+\frac{\partial p_{1}}{\partial L_{0}}(1+r)^{-1} L_{1} \\
& =p_{0}\left(1+\frac{1}{n_{00}}+(1+r)^{-1} \frac{R_{1}}{R_{0}} \cdot \frac{1}{n_{01}}\right) \leq s+q\left[1+(1+r)^{-1}\right]+\lambda \\
M R_{1} & =p_{1}+\frac{\partial p_{1}}{\partial L_{1}} L_{1}+(1+r) \frac{\partial p_{0}}{\partial L_{1}} L_{0} \\
& =p_{1}\left(1+\frac{1}{n_{11}}+(1+r) \frac{R_{0}}{R_{1}} \frac{1}{n_{10}}\right) \leq s(1+r)+q+\lambda
\end{aligned}
$$


where $R_{i}$ is total sales revenue in period $i\left(R_{i}=p_{i} L_{i}\right)$, and $\eta_{i j}$ is the elasticity of demand in period $i$ with respect to $p_{j}$, and $\lambda$ is the Lagrangean multiplier associated with the constraint on developable land, with $\lambda \geq 0$.

One important result that does follow from the first order conditions is that the monopolist is less likely than the competitor to develop all the land. The competitor will be willing to develop if the developed land price less development costs equals the agricultural opportunity costs. The monopolist will not be willing to develop where marginal revenue less development costs equal the agricultural opportunity cost. Since the average (over $T=0,1$ ) marginal revenue earned by 1 and must be less than average price, there must be levels of demand for which the competitive industry will develop all the land, but for which the monopolist will not. In such a case, the monopoly price in each period may exceed the corresponding price under competitive conditions.

Assume now that demand is sufficient for all 1and to be developed within the two periods. ${ }^{13}$ For $\lambda>0$ in equation (26), the monopolist earns a combination of Ricardian rents and returns to market power. This fact would seem to be quite important in view of the tendency of policymakers to see high land prices only as returns to market power. The solution to (21) can, in this case, be characterized by the following relationships:

$$
\left(L_{0}, L_{1}\right)=\left\{\begin{array}{l}
\left([, 0), \text { if } M R_{0}-M R_{7}(1+r)^{-1}>q+\left[s-s(1+r)^{-1}\right]\right. \\
(0, \bar{L}), \text { if } M_{0}-M R_{7}(1+r)^{-1}<q+\left[s-s(1+r)^{-1}\right] \\
\left(L_{0},\left[-L_{0}\right), L_{0} \geq 0, \text { if } M R_{0}-{M R_{7}}_{7}(1+r)^{-1}=q+\left[s-s(1+r)^{-1}\right]\right.
\end{array}\right.
$$

The expressions in (27) are the same as those in (8a), except that 
prices have been replaced by marginal revenues.

Earlier results have demonstrated that the difference between $p_{0}$ and $p_{1}$ determines directly the equilibrium pattern of supply. Assuming land is supplied in each period, the last equations of (27) and (8a) provide an explicit comparison of the equilibrium prices under the two market structures. Letting $p_{j}^{C}$ denote equilibrium market price in period $i$ under competition, and $p_{i}^{M}$ the corresponding price under monopoly, subtracting the conditions for positive supplies in each period in (27) (using (26)) from the equivalent expression in $(8 a)$, we have:

$$
\begin{aligned}
& \left(p_{0}^{C}-p_{0}^{M}\right)-\left(p_{1}^{C}-p_{1}^{M}\right)(1+r)^{-1} \\
& \quad=p_{0}^{M}\left(\frac{1}{n_{00}}+(1+r)^{-1} \frac{R_{1}}{R_{0}} \frac{1}{n_{01}}\right)-p_{1}^{M}(1+r)^{-1}\left(\frac{1}{n_{11}}+(1+r) \frac{R_{0}}{R_{1}} \frac{1}{n_{10}}\right)
\end{aligned}
$$

Since $d\left(L_{0}+L_{1}\right) / d p_{i}<0$ by assumption, if all land is developed under both competition and monopoly, then $\left(p_{0}^{C}-p_{0}^{M}\right)\left(p_{1}^{C}-p_{1}^{M}\right)<0$, and $\left(L_{0}^{C}-L_{0}^{M}\right)\left(L_{1}^{C}-L_{0}^{M}\right)<0$. This is because if the price in each period was higher under monopoly, total demand would be less than $\bar{L}$. In other words, if the monopoly price at $T=1$ exceeds the competitive price in the same period, then the monopoly price in $T=0$ must be less than the corresponding competitive price if total two period demand is to equal $\bar{L}$ in each case. In such a situation, monopoly will lead to a faster rate of 1 and development and a faster rate of price appreciation than would result under competition. Assuming that the bracketed elasticity expressions in (28) are negative (i.e., that marginal revenue as defined here is less than price in each period), the general result is: 


$$
\frac{p_{0}^{M}\left(\frac{1}{n_{00}}+(1+r)^{-1} \frac{R_{1}}{R_{0}} \frac{1}{n_{01}}\right)}{p_{1}^{M}(1+r)^{-1}\left(\frac{1}{n_{11}}+(1+r) \frac{R_{0}}{R_{1}} \frac{1}{n_{10}}\right)}\left\{\begin{array}{l}
<1, p_{0}^{C}>p_{0}^{M}, L_{0}^{C}<L_{0}^{M} \\
>1, p_{0}^{C}<p_{0}^{M}, L_{0}^{C}>L_{0}^{M} \\
=1, p_{0}^{C}=p_{0}^{M}, L_{0}^{C}=L_{0}^{M}
\end{array}\right.
$$

Under fairly general sets of assumptions, there seems to be no reason for believing that this term would be either greater or less than one. The conclusion of this section, therefore, is that, with a fixed stock ofland to be developed within a given time horizon, a monopolist may or may not develop land faster than a perfect competition industry depending upon the relevant elasticities given above. This is explained by the fact that the rate of supply and the rate of price increase work in opposite directions. The optimal trade off between these two depends on these demand elasticities. The only thing we can be certain about is that, unless (29) equals 1, equilibrium prices, rate of price appreciation, and rate of development will be different from the competitive equilibrium. Thus unless (29) equals 1, resources will be misallocated. It is possible, however, that demand conditions exist such that (29) equals 1, implying that the competitive and monopoly solutions are identical. Although the monopolist still has market power, he does not find it profitable to exercise it.

Notice that except in the unusual case that the monopoly and competitive solutions are identical, in one period monopoly profits will necessarily be smaller than the corresponding competitive Ricardian rents! This shows that it would be incorrect to attempt to verify the existence of exercised market power by measuring the profits of large landowners in a given period. If competitive prices were known, the difference between the present value of the monopolist's profits and the present value of 
Ricardian rents would measure the present value of the returns to market power.

In Appendix II we present a simple analytic example which compares competitive and monopoly development for linear demand functions.

\section{Taxation and Market Equilibrium - Monopoly}

The effects of property and capital gains taxes under monopoly conditions will be treated very briefly since these effects depend on demand conditions. The monopolist's problem in the case of the property tax is stated as follows:

$$
\begin{aligned}
& \underset{\left\{L_{0}, L_{1}\right\}}{\operatorname{Max}} p_{0} L_{0}+p_{1}(1+r)^{-1} L_{1}-\tau\left(p_{0}-s\right)\left(L_{0}+L_{1}\right)-\tau\left(p_{1}(1+r)^{-1}-s(1+r)^{-1}\right) L_{1} \\
& \quad-s L_{0}-s(1+r)^{-1} L_{1}+q\left(\left[-L_{0}\right)+q(1+r)^{-1}\left(\left[-L_{0}-L_{1}\right)\right.\right. \\
& \text { s.t. } L_{0}+L_{1}-\tau \leqq 0 \quad L_{0}, L_{1} \geq 0 \\
& \quad p_{0}=p_{0}\left(L_{0}, L_{1}\right) \quad p_{1}=p_{1}\left(L_{0}, L_{1}\right)
\end{aligned}
$$

If demand is such that all land is developed and some 1 and is developed in each period, the first order necessary conditions for a maximum give us the following:

$$
\begin{aligned}
& M R_{0}^{*}-M_{1}^{*}(1+r)^{-1}(1-\tau)=q+\left[s-s(1+r)^{-1}(1-\tau)\right] \\
& M R_{0}^{*}=p_{0}\left[1+\left(1-\tau\left(1+\frac{L_{1}}{L_{0}}\right)\right) \frac{1}{n_{00}}+(1+\tau)(1+r)^{-1} \frac{R_{1}}{R_{0}} \frac{1}{n_{01}}\right] \\
& M R_{1}^{*}=p_{1}\left[1+\frac{1}{n_{11}}+\left((1+r) \frac{R_{0}}{R_{1}}-\left(\frac{\tau}{1-\tau}\right)\right) \frac{1}{n_{10}}\right]
\end{aligned}
$$


In the case of the capital gains tax, the monopolist's problem is given as follows:

$$
\begin{aligned}
\operatorname{Max}_{\left.0, L_{1}\right\}} P_{0} L_{0} & +p_{1}(1+r)^{-1} L_{1}-\theta\left(p_{1}-p_{0}\right)(1+r)^{-1} L_{1}-s L_{0}-s(1+r)^{-1} L_{1} \\
& +q\left(\bar{L}-L_{0}\right)+q(1+r)^{-1}\left(\left[-L_{0}-L_{1}\right)\right.
\end{aligned}
$$

Assuming again that all land is developed and some 1 and is developed in each period, the first order necessary conditions give us the following:

$$
\begin{aligned}
& \operatorname{MR}_{0}^{\prime}\left(1+\theta(1+r)^{-1}\right)-\operatorname{MR}_{1}^{\prime}(1+r)^{-1}(1-\theta)=q+\left(s=s(1+r)^{-1}\right) \\
& M R_{0}^{\prime}=p_{0}\left[1+\left(1-\theta(1+r)^{-1}\right)^{-1}\left(\frac{1}{n_{00}}+\frac{R_{1}}{R_{0}} \frac{1}{n_{01}}\right)\right] \\
& M R_{1}^{\prime}=p_{1}\left[1+\frac{1}{n_{11}}+(1+\theta)^{-1}\left((1+r) \frac{R_{0}}{R_{1}}+\theta \frac{p_{0}}{p_{1}}\right) \frac{1}{n_{10}}\right]
\end{aligned}
$$

The rate of price appreciation and the pattern of 1 and development resulting from the institution of these taxes in the monopoly case cannot be compared to the no tax equilibrium without specific knowledge of the demand elasticities. As in the case of comparing monopoly equilibrium to competitive equilibrium, we see that the results depend upon the nature of demand. Once again, the explanation lies in the price quantity trade off. In the case of the capital gains tax, for example, tax payments equal $\theta\left(p_{1}-p_{0}\right) L_{1}$. If the monopolist increases sales in $T=0, L_{1}$ decreases but $\left(p_{1}-p_{0}\right)$ must increase. This latter effect is not considered by competitors who take prices as given. Whether or not it is profitable for the monopolist to increase sales at $T=0$ depends on the nature of this trade off. Determinate effects of this tax in the competitive case then become indeterminate in 
the monopoly situation.

\section{Summary and Conclusions}

1. For low levels of demand, a competitive development industry will supply developed land at a price equal to the present value of agricultural returns plus development costs. For higher levels of demand for 1 and in fixed supply, developers will supply land such that the price of developed land appreciates at a rate equal to the developer's discount rate, $r$, less an amount relating the opportunity costs of land development to current developed land prices. Ricardian rents on land appreciate at rate $r$ and the rate of price appreciation approaches $r$ as the price of developed 7 and becomes high relative to land's yearly return from agriculture. Given the dynamic nature of demand, it is also noted that Ricardian rents on land are generally positive despite the fact that only a small part of total supply may be transacted in any one period.

2. With land in fixed supply, a monopolist is less likely to develop all his land than a competitive development industry within the same time horizon. If demand is sufficient for the monopolist to profitably develop all his land, however, he may develop it faster than the competitive industry. The monopolist's problem is to weigh the trade off between a low rate of development and a high rate of price appreciation. In such a situation, the existence of monopoly power is not sufficient for the exercise of monopoly power and, therefore, for resource misallocation. If market power is exercised and all land is developed, then in one period monopoly profits are lower than the associated competitive Ricardian rents.

3. In the competitive case, a property tax or a capital gains tax 
will reduce the initial period price of developed land. The property tax will also reduce the second period price and increase the equilibrium rate of price appreciation. The capital gains tax will lead to a higher rate of development and a higher rate of price appreciation than would prevail in the absence of the tax. The capital gains tax cannot reduce the total amount of land developed over time.

4. In the situation where demand is sufficient for competitive developers to profitably develop all their land, it does not follow that the incidence of these taxes falls entirely on the developers. The optimal trade off depends on the exact nature of consumer demand. Al though their total supply is perfectly inelastic, these taxes lead to an inter-period reallocation of development. The present value of total consumer payments forland will be altered and may decrease, a situation that might be termed a negative tax incidence.

5. The effect of these taxes on the monopolist's supply is indeterminate. With an ad valorem tax on capital gains, for example, the monopolist can reduce the quantity component of total capital gains (equal to price change times quantity) only at the expense of increasing the price change component. 


\section{Appendix I}

This section will provide a discussion of the comparative statics properties derived in the section on demand. A difficulty is that even the assumptions that 1 and in each period is a normal good and that the composite consumption good is a net substitute for 1 and in each period may not guarantee one property of demand that we have assumed. This is the property that a rise in $\mathrm{p}_{0}$, ceteris paribus, reduces the total two period demand for land $\left(2\left(L_{0}+L_{1}\right) / \partial p_{0}<0\right)$. We will analyze this property for an individual consumer's demand functions. The problem then is that if $L_{0}$ and $L_{1}$ are gross substitutes, the (positive) pure-cross-substitution effect $\left(\partial L_{l} / \partial p_{0}\right)_{\bar{u}}$ may outweigh the (negative) pure-own-substitution effect $\left(\partial L_{0} / \partial p_{0}\right)_{\bar{u}}$ and the income effects $L_{0}\left(\partial L_{i} / \partial Y_{0}\right)$. It can be shown, however, that this possibility ceases to exist if the equilibrium rate of price appreciation is high enough.

A well-known demand theorem states that the sum of price-weighted pure-substitution effects must equal zero. In this context, that reduces to

$$
p_{0}\left(\frac{\partial L_{0}}{\partial p_{0}}\right)_{\bar{u}}+p_{1}(1+i)^{-1}\left(\frac{\partial L_{1}}{\partial p_{0}}\right)_{\bar{u}}+\left(\frac{\partial C_{0}}{\partial p_{0}}\right)_{\bar{u}}+(1+i)^{-1}\left(\frac{\partial C_{1}}{\partial p_{0}}\right)_{\bar{u}}=0
$$

Since $p_{0}>p_{1}(1+i)^{-1}$ when the equilibrium is characterized by positive land sales in each period, the assumption that the composite consumption good in any period and $L_{0}$ are net substitutes $\left(\left(\partial C_{j} / \partial p_{0}\right)_{\bar{u}}>0\right)$ is not sufficient to imply the absolute value of $\left(\partial \mathrm{L}_{0} / \partial \mathrm{p}_{0}\right)_{\bar{u}}$ outweighs a positive $\left(\partial L_{1} / \partial p_{0}\right)_{\bar{u}}$. (The same argument does establish that $\left.\partial\left(L_{0}+L_{1}\right) / \partial p_{1}<0.\right)$ The sum of the two effects, however, must become negative as the rate of price appreciation approaches $i$. Adding the influence of income effects then guarantees that, for a range of rates of price appreciation less than $i$, 
$\partial\left(L_{0}+L_{1}\right) / \partial p_{0}<0$. It should also be noted that this property will hold for all rates of price appreciation that give interior solutions for many types of utility functions such as additive forms.

A second problem referred to in the section on market equilibrium deals with the possibility that all land will be withheld until $T=1$. From the first order conditions in (3), a price configuration such that $L_{0}=0$ implies that $U_{02}+U_{12}-\lambda p_{0}<0$. Manipulation of these conditions gives us the result that $L_{0}=0$ and $L_{7}>0$ if and only if:

$$
\frac{p_{1}-p_{0}}{p_{0}}<i-\frac{U_{02}}{U_{01}}(1+i) / p_{0}
$$

where $U_{02} / U_{01}$ is the positive marginal rate of substitution between the composite commodity and land in $T=0$. Similarly, the supply conditions given in (8) states that equilibrium will be characterized by $\left(L_{0}=0, L_{1}>0\right)$ if and only if:

$$
\frac{p_{1}-p_{0}}{p_{0}}>r-[q(1+r)+r s] / p_{0}
$$

This equilibrium is less likely the higher the developers' discount rate relative to the consumers' rate and the higher the price of developed land relative to the return from agricultural land use. It should also be noted that with many commonly-used functional forms such as the Cobb-Douglas, the marginal rate of substitution $U_{02} / U_{01}$, becomes very large as $L_{0}$ approaches zero, implying that an equilibrium characterized by $L_{0}=0$ cannot exist. 


\section{Appendix II}

This section will provide a simple analytic example that shows how the timing of land sales under conditions of monopoly will differ from the timing ofland sales under conditions of perfect competition.

The demand functions for 1 and in each period are assumed to be given by the following:

$$
\begin{aligned}
& L_{0}=\alpha_{0}-b p_{0}+\gamma b p_{1} \\
& L_{1}=\alpha_{1}-b p_{1}+\gamma b p_{0}
\end{aligned}
$$

For the time being, it is assumed that $0<\gamma<1 .{ }^{14} \alpha_{1}$ might be larger relative to $\alpha_{0}$ if, for example, consumer tastes shift in favour of housing over time.

For algebraic simplicity, it is assumed that agricultural opportunity costs and development costs equal zero. The monopolist's problem is to maximize the following function:

$$
\begin{aligned}
\operatorname{Max} p_{0}(1+r) L_{0}+p_{1} L_{1}+\lambda\left(\left[-L_{0}-L_{1}\right)\right. & \\
= & \left(\alpha_{0}-b p_{0}+\gamma b p_{1}\right)(1+r) p_{0}+\left(\alpha_{1}-b p_{1}+\gamma b p_{0}\right) p_{1} \\
& +\lambda\left(\left[-\left(\alpha_{0}+\alpha_{1}\right)-(1-\gamma) b p_{0}-(1-\gamma) b p_{1}\right)=0\right. \\
\frac{\partial}{\partial p_{0}}= & \left(\alpha_{0}-2 b p_{0}+\gamma b p_{1}\right)(1+r)+\gamma b p_{1}-\lambda(1-\gamma) b=0 \\
\frac{\partial}{\partial p_{1}}= & \left(\alpha_{1}-2 b p_{1}+\gamma b p_{0}\right)+\gamma b(1+r) p_{0}-\lambda(1-\gamma) b=0
\end{aligned}
$$


Manipulation of these first order conditions gives us the following relationships:

$$
\frac{1}{\sigma}\left(\alpha_{0}(1+r)-\alpha_{1}\right)=\Delta p_{0}-p_{1}
$$

where

$$
\begin{aligned}
& \sigma=(2+r) \gamma b+2 b>0 \\
& \Delta=\frac{(2+r) \gamma b+(1+r) 2 b}{(2+r) \gamma b+2 b}<(1+r)
\end{aligned}
$$

A sufficient (but not necessary) condition for $p_{1}$ to be greater than $p_{0}$ is that the intercept term be growing faster than the discount rate $r$. Since $\Delta<(1+r)$, however, this is not sufficient for the equilibrium price ratio to exceed $(1+r)$, the ratio that will prevail in this example under competitive conditions.

The conclusion is that, with linear demand of this type, growth in demand below the market rate of interest will always lead the monopolist to supply less land in initial periods than would be supplied by a competitive market. On the other hand, for growth in demand sufficiently in excess of the discount rate, a monopolist will supply relatively more land in initial periods, leading to a rate of price increase in excess of the discount rate. Allowing the slope coefficients (b) and the cross effects coefficients $(\gamma)$ to vary between periods will change the numerical values of $\sigma$ and $\Delta$ in (V3) but will not change the direction of the relationship, provided that $\gamma>-2 /(2+r)$. $\gamma$ can, of course, be negative if the pure cross substitution effect is less than the absolute value of the cross income effect. 


\section{FOOTNOTES}

* This paper represents part of a study funded by the Ontario Economic Council. The authors gratefully acknowledge this support.

1The term "developer" is often reserved for a land investor who makes improvements to land (e.g., subdivision and lot servicing) before selling that 1 and. "Speculators" on the other hand, are often thought of as land investors who buy and sell land without making improvements in hopes of realizing pure capital gains. Under these definitions, developers may be thought of as speculators who also engage in land improvement. Realizing pure capital gains on land is typically just as much a part of a developer's activities as making profits on land improvements. This paper will, therefore, restrict itself to a consideration of land "developers," who are assumed to pursue profits both from pure capital gains and from 1 and improvements.

${ }^{2}$ An example of legislation which embodies this view of the 1 and development process is the Ontario Land Speculation Tax, which was enacted in 1974. This Act taxes the capital gains on sales of land which have not been suitably developed by the seller.

${ }^{3}$ All of the works listed under References in some way deal with the issue of the behavior of land investors and how they perceive demand conditions. See, for example, Bahl (1968), Bentick (1972), Clawson (1962), Morris (1969), and Shoup (1969). For an analysis of land investment when land is a factor of production, see Nichols (1970). 
4 Many of the papers referenced below arrived at questionable results due to their partial equilibrium nature. More specifically, they assume that "demand for land" grows monotonically over time (interpreted to mean an outward shift in Marshallian demand curve) in a way that is most conveniently expressed by a concave function $V(T)$ which gives the value of land holdings at time T (see, for example, Bahl (1968) and Shoup (1969). This approach assumes away all interesting aspects of the problem and guarantees a number of results a priori. For example, the (unjustified) assumption that $V(T)$ is strictly concave ensures us that the institution of the property tax will reduce the optimal length of time that an investor will hold land. For one attempt to actually explain the equilibrium increase in valuation over time, see Bentick (1972).

${ }^{5}$ For the purposes of this paper, the assumption of two periods is important in that it assumes a fixed time horizon but not in that it assumes only two periods. All conclusions will be essentially valid in a multiperiod model. Also, it should be noted that landowners may sell land among themselves as may consumers. Any sale by a landowner to a consumer, however, is assumed to be irreversible.

${ }^{6}$ Although this assumption is admittedly unrealistic, it is true that the building and development industries are often quite separate. In Toronto, for example, few developers have building divisions of any consequence. The building industry is composed of a great many small companies, most of whom buy serviced building lots for immediate construction. Further, total holdings of undeveloped land by individuals and builders is small compared with holdings by development companies. See Markusen and 
Scheffman (1975b).

${ }^{7}$ The purpose of this assumption is to reduce the general equilibrium model to the problem of determining a single relative price.

${ }^{8}$ This model is concerned with the determination of relative prices. Changes in nominal prices are found by multiplying through equation (2) in each period by a price index.

${ }^{9}$ of course, if $p_{1}$ is an expected price (a random variable) then plans made at the beginning of the initial period must be revised when the actual price is observed in the second period.

${ }^{10}$ Besides $r$ including the appropriate risk premium, this is one point at which simple uncertainty could be introduced into the model. If $p_{1}$ is made a random variable reflecting the landowner's expectations, for example, maximization of expected profits will lead to the same condition as given in (7) except that $p_{1}$ will be replaced by $E\left(p_{1}\right)$ (the expected value of $p_{1}$ ). If a risk preference function is introduced which is characterized by risk aversion, (7) will be replaced by some expression involving the expected utility of sales revenue.

${ }^{11}$ It should also be noted that the change in initial period land price in response to the property tax relates to a number of discussions concerning capitalization of the property tax. See, for example, Oates (1969). It should also be noted that government involvement of any sort in the land market creates another form of uncertainty in that government policy is subject to frequent and arbitrary changes. This issue has been 
raised by Bahl (1968).

${ }^{12}$ Two recent studies of the Toronto area have suggested that a small number of the large developers own a large percentage of the available land. A candidate running for the provincial parliament of Ontario claimed that two developers owned more than $90 \%$ of the available land in London, Ontario (a city of approximately 250,000). As in any discussion of monopoly, the analysis and conclusions developed in this section are applicable in oligopolistic situations if the landowner in question either behaves in a Cournot fashion or has fixed expectations about the reactions of other landowners to his sales behavior. With more sophisticated behavior, a game theoretic approach is needed.

${ }^{13}$ This is not an unreasonable assumption in the context of this perfect certainty model, since otherwise it would mean that the monopolist had intentionally accumulated more land than he planned to sell.

${ }^{14}$ This is equivalent to assuming that the pure cross substitution effect is larger than the absolute value of the pure cross income effect. 


\section{REFERENCES}

[1] Bahl, R. H., "A Land Speculation Model: The Role of the Property Tax as a Constraint on Urban Sprawl," Journal of Regional Science 8 (1968), 199-208.

[2] Bentick, B. L., "Improving the Allocation of Land Between Speculators and Users: Taxation and Paper Land," The Economic Record 48 (1972).

[3] Clawson, M., "Urban Sprawl and Speculation in Suburban Land," Land Economics 38 (1962).

[4] Davidson, B. R., "The Effects of Land Speculation on Supply of Housing in England and Wales," Urban Studies 12 (1975, $97-99$.

[5] Harriss, C. L., "Land Value Increment Taxation: Demise of the British Betterment Levy," National Tax Journal 25 (1972), $567-572$.

[6] Markusen, J.R. and D. T. Scheffman, "An Analysis of Structure and Speculation in Urban Land Markets," a study for the Ontario Economic Council, forthcoming (1975b).

[7] Markusen, J. R. and D. T. Scheffman, "Ownership Concentration and Market Power in the Urban Land Market: A Theoretical Analysis," University of Western Ontario Working Paper (1975a).

[8] Morris, R. E., "Fiscal Controls of Land Monopoly," The American Journal of Economics and Sociology 28 (1969), 77-92. 
[9] Netzer, D., Economics of the Property Tax . (Washington, Brookings Institution, 1966).

[10] Neutze, G. M., The Price of Land and Land Use Planning: Policy Instruments in the Urban Land Market (Paris: OECD, Environment Directorate, 1973).

[11] Nichols, D. A., "Land and Economic Growth," American Economic Review 60 (1970, 1065-1083.

[12] Oates, W. E., "The Effects of Property Taxes and Local Public Spending on Property Values," Journal of Political Economy 77 (1969).

[13] Shoup, D. C., "Advance Land Acquisition by Local Governments: A Cost-Benefit Analysis," Yale Economic Essays 9 (1969), 147-207.

[14] Smith, L. B., "The Ontario Land Speculation Tax: An Anatomy of an Unearned Increment Land Tax," University of Toronto Working Paper.

[15] Smith, R. S., "Land Prices and Tax Policy: Review and Analysis," University of Alberta Working Paper, 1975.

[16] Turvey, R., The Economics of Real Property (London: George Allen and Unwin, Ltd., 1957). 


\section{RESEARCH PROGRAM: \\ IMPACT OF THE PUBLIC \\ SECTOR ON LOCAL ECONOMIES}

The Department of Economics, University of Western Ontario, has recentiy mounted a long-term research program on the Impact of the Public Sector on Local Economies. The program publishes Discussion Papers and Research Studies. Copies may be obtained by writing:

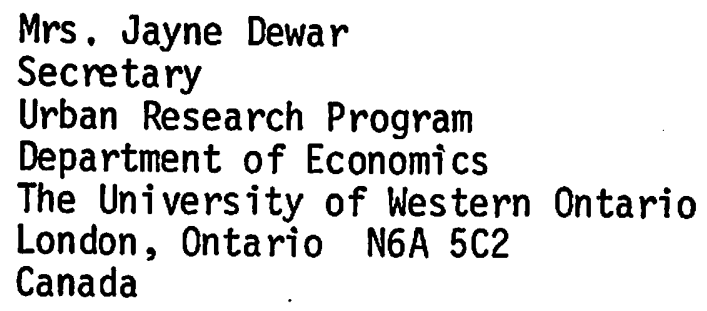

The following Discussion Papers and Research Studies are currently available:

\section{DISCUSSION PAPERS:}

001 P. T. Chinloy, "Hedonic Prices and Age Deterioration in Urban and Suburban Housing" (September 1975).

002 M. W. Frankena, "Al ternative Models of Rent Control" (September 1975).

003 J. R. Markusen and D. T. Scheffman, "Ownership Concentration and Market Power in Urban Land Markets" (October 1975).

004 A. J. Robson, "The Effect of Urban Structure on Ambient Pollution" (October 1975).

005 J. R. Markusen and D. T. Scheffman, "The Timing of Residential Land Development: A Generai Equil ibrium Approach" (November 1975).

RESEARCH STUDIES:

01 G. W. Davies and P. L. Jackson, "A Model of the Urban Housing and Residential Land Markets" (September 1975).

02 G. P. Schaefer, "The Urban Area Production Function and the Urban Hierarchy: The Case of Saskatchewan" (October 1975). 